\title{
Can phosphorylation of phosphatidate phosphohydrolase by a cyclic AMP- dependent mechanism regulate its activity and subcellular distribution and control hepatic glycerolipid synthesis?
}

\author{
Simon C. BUTTERWITH, Ashley MARTIN and David N. BRINDLEY \\ Department of Biochemistry, University of Nottingham Medical School, Queen's Medical Centre, \\ Nottingham NG7 2UH, U.K.
}

(Received 2 April 1984/Accepted 9 May 1984)

1. Incubating the particle-free supernatant of rat liver with alkaline phosphatase decreased the activity of phosphatidate phosphohydrolase by $21-29 \% .2$. When the particle-free supernatant was incubated with various combinations of $\mathrm{Mg}^{2+}, \mathrm{ATP}$, cyclic AMP and cyclic AMP-dependent protein kinase this failed to alter significantly phosphatidate phosphohydrolase activity under the conditions employed. 3. The incubation of hepatocytes in monolayer culture with $0.5 \mathrm{~mm}-8-(4-$ chlorophenylthio)adenosine $3^{\prime}, 5^{\prime}$-monophosphate increased the total activity of phosphatidate phosphohydrolase as measured in vitro. This also decreased the proportion of the phosphohydrolase that was associated with the membrane fraction of the cells and increased that in the cytosolic fraction. 4. Adding $1 \mathrm{~mm}$-oleate to the hepatocytes promoted the translocation of phosphatidate phosphohydrolase from the cytosol to the membrane-associated compartment. Oleate overcame the effect of the cyclic AMP analogue in favouring the cytosolic distribution of the phosphohydrolase. 5. These results are discussed in relation to the interaction of hormonal balance and substrate supply in controlling the synthesis of phosphatidylcholine and triacylglycerol in the liver in stress and in diabetes. It is proposed that the cytosolic phosphatidate phosphohydrolase activity represents a reservoir of potential activity that becomes expressed when the enzyme translocates to the membranes on which the synthesis of glycerolipids occurs.

PAP is thought to be an important enzyme in the regulation of glycerolipid, and particularly of triacylglycerol, synthesis in the liver. This hypothesis is supported by the observation that the activity of PAP changes under different physiological conditions to a greater extent than does that of the other enzymes involved in triacylglycerol synthesis. In general, PAP activity parallels the altered potential of the liver to produce triacylglycerol. However, whether that potential is expressed will depend upon other factors, of which the most important is probably the rate of substrate supply (Brindley \& Sturton, 1982).

Several mechanisms have been described by which the activity of PAP in the liver can be controlled. First, the synthesis of PAP is stimulated by

Abbreviations used: PAP, phosphatidate phosphohydrolase (EC 3.1.3.4); CPT-cAMP, 8-(4-chlorophenylthio)adenosine $3^{\prime}, 5^{\prime}$-monophosphate. glucocorticoids (Lehtonen et al., 1979; Jennings et al., 1981), and this effect is antagonized by insulin (Lawson et al., 1982a,b). Secondly, there is a rapid stimulation of PAP activity and triacylglycerol synthesis that is seen when hepatocytes are incubated with vasopressin (Pollard \& Brindley, 1984). A similar effect is probably produced by other hormones that mobilize intracellular $\mathrm{Ca}^{2+}$. Thirdly, the incubation of hepatocytes with fatty acids stimulates PAP activity (Lamb \& McCue, 1983; Cascales et al., 1984). This stimulation is accompanied by the translocation of PAP from the cytosol to a membrane-associated compartment (Cascales et al., 1984) and an increase in the rate of synthesis of triacylglycerol and phosphatidylcholine (Pelech et al., 1983a,b). It is thought that the binding of PAP and CTP:phosphocholine cytidylyltransferase to the membrane on which glycerolipid synthesis is occurring is responsible for this increased rate of glycerolipid synthesis 
(Pelech et al., 1983a,b; Cascales et al., 1984). By contrast, the cytosolic form of these enzymes represents a metabolically inactive form which is held in reserve. It was suggested that the effect of fatty acids in stimulating PAP activity may involve the action of cyclic GMP (Lamb \& McCue, 1983). Finally, it has been proposed that PAP activity can be decreased by a cyclic AMP-dependent phosphorylation (Berglund et al., 1982). However, another study has shown that PAP activity was increased when rat livers were perfused for $1 \mathrm{~h}$ with dibutyryl cyclic AMP in the presence of $0.5 \mathrm{~mm}$ oleate (Soler-Argilaga et al., 1978). It is also known that the cyclic-AMP-induced inhibition of triacylglycerol synthesis is reversed by fatty acids (Pelech et al., 1983b).

The present study investigates further whether the activity of PAP can be modified in the short term by a cyclic-AMP dependent mechanism and, if so, how this effect is related to that seen with fatty acids.

\section{Experimental}

\section{Animals and materials}

The source of most of these has already been described (Cascales et al., 1984). In addition, alkaline phosphatase (type VII-S from bovine intestinal mucosa, and type III-R from Escherichia coli), histone IIA, adenosine $5^{\prime}-[\beta \gamma$-methylene $]$ triphosphate and ATP were obtained from Sigma (London) Chemical Co., Poole, Dorset, U.K., Chlorpromazine was a gift from May and Baker, Dagenham, Essex, U.K. and [ $\gamma^{-32}$ P]ATP was from Amersham International, Amersham, Bucks., U.K. Cyclic AMP and CPT-cAMP were from Boehringer Corp. (London), Lewes, E. Sussex, U.K. The cyclic AMP-dependent protein kinase holoenzyme was a gift from Drs. M. Rider and E. D. Saggerson. It was prepared by the method of Brostrom et al. (1969) except that the calcium phosphate gel stage was omitted (Rider \& Saggerson, 1983).

Preparation of the particle-free supernatant of rat liver

This was prepared from the livers of female Wistar rats without perfusion by the method of Sturton et al. (1981) except that phenylmethanesulphonyl fluoride was omitted.

\section{Preparation and incubation of hepatocytes and their lysis with digitonin}

The methods used are those described by Cascales et al. (1984). Cytosolic enzymes were released from the hepatocytes by a $4 \mathrm{~min}$ incubation at $4^{\circ} \mathrm{C}$ with $4.07 \mathrm{~mm}$-digitonin dispersed in
$0.25 \mathrm{M}$-sucrose containing $0.5 \mathrm{mM}$-dithiothreitol and 10mM-Hepes [4-(2-hydroxyethyl)-1piperazine-ethanesulphonic acid] adjusted to pH7.4 with $\mathrm{KOH}$ (Cascales et al., 1984). The procedure was based on that originally described by Mackall et al. (1979).

\section{Determination of PAP activity from isolated hepatocytes}

This was determined by using a mixed emulsion of phosphatidylcholine and phosphatidate labelled with $\left[{ }^{3} \mathrm{H}\right]$ palmitate. The reaction was stopped and $\left[{ }^{3} \mathrm{H}\right]$ diacylglycerol was isolated as described by Pollard \& Brindley (1984). Each assay contained in a final vol. of $0.25 \mathrm{ml}: 100 \mathrm{~mm}$-Tris adjusted to pH7.4 with $\mathrm{HCl}, 1 \mathrm{~mm}$-dithiothreitol, $0.1 \mathrm{~mm}$ EGTA, $0.6 \mathrm{~mm}-\left[{ }^{3} \mathrm{H}\right]$ phosphatidate $(0.68 \mathrm{Ci} / \mathrm{mol})$, $0.4 \mathrm{~mm}$-phosphatidylcholine, $0.5 \mathrm{mg}$ of fatty-acidpoor bovine serum albumin and an optimum concentration of $\mathrm{MgCl}_{2}$, which in this case was $1.2 \mathrm{mM}$. The incubation tubes were shaken at $37^{\circ} \mathrm{C}$ for $60 \mathrm{~min}$.

Determination of the activities of lactate dehydrogenase and cyclic AMP-dependent protein kinase

These enzymes were assayed by the methods of Saggerson \& Greenbaum (1969) and Reimann et al. (1971). One unit of protein kinase activity was the amount of enzyme that catalysed the incorporation of $1 \mathrm{nmol}$ of [ $\left.{ }^{32} \mathrm{P}\right]$ phosphate into histone protein $/ \mathrm{min}$ at $30^{\circ} \mathrm{C}$.

\section{Determination of alkaline phosphatase activity}

Before use the alkaline phosphatase suspensions were dialysed overnight against $0.25 \mathrm{M}$-sucrose containing $0.2 \mathrm{~mm}$-dithiothreitol, $0.1 \mu \mathrm{M}-\mathrm{ZnSO}_{4}$ and $1 \mu \mathrm{M}-\mathrm{MgCl}_{2}$ which had been adjusted to $\mathrm{pH} 7.4$ with $\mathrm{KHCO}_{3}$. The enzyme was assayed in a final vol. of $1 \mathrm{ml}$ of the sucrose medium containing $20 \mathrm{mM}$-p-nitrophenylphosphate and $2 \mathrm{mM}-\mathrm{MgCl}_{2}$ at $37^{\circ} \mathrm{C}$. The initial rate of increase in $A_{405}$ was monitored on a Gilford $240 \mathrm{~A}$ scanning spectrophotometer. One unit of activity was defined as hydrolysing $1 \mu \mathrm{mol}$ of $p$-nitrophenylphosphate $/ \mathrm{min}$ under these conditions. This was calculated by using an $\varepsilon_{405}$ of $18500 \mathrm{M}^{-1} \cdot \mathrm{cm}^{-1}$ for the $p$-nitrophenol that was formed.

Treatment of the particle-free supernatant with alkaline phosphatase from bovine intestine and measurement of PAP activity

Alkaline phosphatase from bovine intestine was incubated in $0.25 \mathrm{M}$-sucrose, adjusted to $\mathrm{pH} 7.4$ with $\mathrm{KHCO}_{3}$ and containing $0.2 \mathrm{mM}$-dithiothreitol and $2 \mathrm{mM}-\mathrm{MgCl}_{2}$, for $45 \mathrm{~min}$. This procedure doubled the activity of the enzyme. The particlefree supernatant from rat liver $(6.25 \mathrm{mg}$ of protein $/ \mathrm{ml}$ ) was then incubated in $0.25 \mathrm{M}$-sucrose 
adjusted to $\mathrm{pH} 7.4$ with $\mathrm{KHCO}_{3}$ and containing $0.2 \mathrm{~mm}$-dithiothreitol, $2 \mathrm{mM}-\mathrm{MgCl}_{2}$ and up to 15 units of alkaline phosphatase for $15 \mathrm{~min}$ at $37^{\circ} \mathrm{C}$. Samples $(15 \mu \mathrm{l})$ were then taken for analysis of PAP activity in an assay system that was designed to prevent the hydrolysis of phosphatidate to diacylglycerol by the preparation of alkaline phosphatase. This system contained in a final volume of $250 \mu \mathrm{l}$ : $100 \mathrm{~mm}$-Tris adjusted to $\mathrm{pH} 7.4$ with $\mathrm{HCl}$, $0.6 \mathrm{~mm}-\left[{ }^{3} \mathrm{H}\right]$ phosphatidate $(0.45 \mathrm{Ci} / \mathrm{mol})$ as a mixed emulsion with $0.3 \mathrm{~mm}$-phosphatidylcholine, $1 \mathrm{mM}$ dithiothreitol, $0.5 \mathrm{mg}$ of fatty-acid-poor bovine serum albumin, $0.1 \mathrm{~mm}$-EGTA, $0.12 \mathrm{~mm}-\mathrm{MgCl}_{2}$ (from the preincubation), $0.3 \mathrm{~mm}$-chlorpromazine and $2 \mathrm{~mm}$-glycerol 2-phosphate. The tubes were shaken at $37^{\circ} \mathrm{C}$ for $15 \mathrm{~min}$ and the reactions were then stopped and the radioactive diacylglycerol was purified and determined (Pollard \& Brindley, 1984). The chlorpromazine was added at an optimum concentration so as to replace the requirement of PAP for $\mathbf{M g}^{2+}$ (Bowley et al., 1977; Sturton \& Brindley, 1980). It should not however facilitate the action of the alkaline phosphatase. Any remaining action of alkaline phosphatase on phosphatidate was further decreased by adding the glycerol 2-phosphate as a competitive inhibitor. Consequently, the formation of diacylglycerol in control incubations that contained alkaline phosphatase, but not PAP, was below the level of detection.

Incubation of the particle-free supernatant of rat liver with alkaline phosphatase from $E$. coli and the detection of PAP activity

This method was adopted so as to follow a procedure similar to that of Berglund et al. (1982). The particle-free supernatant of rat liver $(425 \mu \mathrm{g}$ of protein) was incubated in a vol. of $190 \mu \mathrm{l}$ containing: $132 \mathrm{~mm}$-Tris adjusted to $\mathrm{pH} 7.4$ with $\mathrm{HCl}$, $1.32 \mathrm{mM}$-dithiothreitol, $0.5 \mathrm{mg}$ of fatty-acid-poor bovine serum albumin, $6.6 \mathrm{mM}-\mathrm{MgCl}_{2}$ and $0.13 \mathrm{mM}$-EGTA in the presence or absence of 10 units of alkaline phosphatase from $E$. coli and $5.58 \mathrm{~mm}$-imidazole adjusted to $\mathrm{pH} 7.4$ with $\mathrm{HCl}$ and containing $0.78 \mathrm{mM}$-dithiothreitol for $15 \mathrm{~min}$ at $37^{\circ} \mathrm{C}$. The addition of this imidazole buffer alone had no effect on PAP activity (results not shown). The PAP assay was then initiated by adding $60 \mu \mathrm{l}$ of water containing a mixed emulsion of $0.6 \mathrm{~mm}$ $\left[{ }^{3} \mathrm{H}\right]$ phosphatidate $(0.45 \mathrm{Ci} / \mathrm{mol})$ plus $0.3 \mathrm{~mm}$-phosphatidylcholine and the incubation was continued for a further $15 \mathrm{~min}$ at $37^{\circ} \mathrm{C}$ with shaking. The PAP assay therefore contains a concentration of $5 \mathrm{mM}$ $\mathrm{MgCl}_{2}$, which was found to be optimum in this system (Sturton et al., 1981; Butterwith et al., 1984). The assays were stopped and the $\left[{ }^{3} \mathrm{H}\right]$ diacylglycerol analysed as described by Pollard \& Brindley (1984). The formation of $\left[{ }^{3} \mathrm{H}\right]$ diacyl- glycerol in control incubations containing 10 units of alkaline phosphatase but no added PAP was $10 \mathrm{nmol} / \mathrm{min}$ per $\mathrm{ml}$ of the preincubation mixture. This value was subtracted as a blank from the PAP activity in the combined incubations.

Incubation of the particle-free supernatant with combinations of $\mathrm{MgCl}_{2}, \mathrm{ATP}$, cyclic $\mathrm{AMP}$ and cyclic AMP-dependent protein kinase

Protein from the particle-free supernatant $(3.25 \mathrm{mg}$ of $\operatorname{protein} / \mathrm{ml})$ was incubated in $0.25 \mathrm{M}$ sucrose adjusted to $\mathrm{pH} 7.4$ with $\mathrm{KHCO}_{3}$ and containing $0.2 \mathrm{~mm}$-dithiothreitol with other additions that are indicated in Table 2 for $15 \mathrm{~min}$ at $37^{\circ} \mathrm{C}$. Samples of this preincubation mixture $(25 \mu \mathrm{l})$ were then assayed for PAP activity in an incubation mixture of $250 \mu \mathrm{l}$ containing: $100 \mathrm{mM}$-Tris adjusted to pH7.4 with $\mathrm{HCl}, 1 \mathrm{~mm}$-dithiothreitol, $0.1 \mathrm{mM}$ EGTA, a mixed emulsion of $0.6 \mathrm{~mm}-\left[{ }^{3} \mathrm{H}\right]$ phosphatidate $(0.45 \mathrm{Ci} / \mathrm{mol})$ plus $0.3 \mathrm{~mm}$-phosphatidylcholine, $0.5 \mathrm{mg}$ of fatty-acid-poor bovine serum albumin and $5 \mathrm{mM}-\mathrm{MgCl}_{2}$. The incubations were shaken for $15 \mathrm{~min}$ at $37^{\circ} \mathrm{C}$ and the $\left[{ }^{3} \mathrm{H}\right]$ diacylglycerol was extracted and determined (Pollard \& Brindley, 1984). In other parallel incubations $5 \mathrm{mM}-\left[\gamma^{-32} \mathrm{P}\right] \mathrm{ATP}(6-8 \mathrm{Ci} / \mathrm{mol})$ was used in combination with the other additions and the incorporation of ${ }^{32} \mathrm{P}$ into protein was measured (Walsh et al., 1971) at time intervals of up to $30 \mathrm{~min}$. The maximum incorporation was achieved between 5 and $15 \mathrm{~min}$.

\section{Results}

Effect of alkaline phosphatase on the PAP activity in the particle-free supernatant of rat liver

Samples of the particle-free supernatant of rat liver were preincubated with alkaline phosphatase in order to test whether PAP is a phosphoprotein and whether its dephosphorylation would alter its activity. The first experiments were performed with alkaline phosphatase from bovine intestine. PAP was then assayed under conditions in which the alkaline phosphatase itself produced no detectable conversion of phosphatidate to diacylglycerol. Preincubation with 5-15 units of alkaline phosphatase decreased the PAP activity by an average of $21-29 \%$ (Table $1 a$ ). Since these results were the opposite of those expected from the work of Berglund et al. (1982), it was decided to try to follow their method more closely.

The particle-free supernatant was incubated with alkaline phosphatase from $E$. coli and an imidazole buffer. The subsequent procedure used for the determination of PAP activity employed $5 \mathrm{mM}-\mathrm{MgCl}_{2}$ which facilitated some conversion of phosphatidate to diacylglycerol by the alkaline phosphatase preparation (see the Experimental 
section). This value was subtracted as a blank where appropriate. Incubation with the alkaline phosphatase from $E$. coli produced essentially the same decrease in PAP activity as was seen with the same amount of enzyme obtained from bovine intestine.

Effects of incubating the particle-free supernatant of rat liver with $\mathrm{MgCl}_{2}, A T P$, cyclic $A M P$ and protein kinase

In order to investigate whether a cyclic AMPdependent phosphorylation of PAP could alter its activity, the particle-free supernatant of rat liver was incubated with combinations of $\mathrm{MgCl}_{2}$, ATP and cyclic AMP. This procedure has been shown to stimulate the phosphorylation of a number of enzymes including acetyl-CoA carboxylase (Greenspan \& Lowenstein, 1967; Carlson \& Kim,

Table 1. Effect of alkaline phosphatase on the activity of $P A P$

The particle-free supernatant of rat liver was incubated with alkaline phosphatase from $(a)$ bovine intestine, or (b) E. coli and PAP activities were determined as described in the Experimental section. Results are expressed as means \pm S.D. for five independent experiments, or means \pm the ranges for two independent experiments. The $100 \%$ value is equivalent to $7.1 \pm 1.9 \mathrm{nmol}$ of diacylglycerol formed $/ \mathrm{min}$ per $\mathrm{mg}$ of protein (mean \pm S.D. from seven independent experiments).

\section{Additions}

(a) None

Alkaline phosphatase (5 units)

Alkaline phosphatase (10 units)

Alkaline phosphatase (15 units)

(b) None

Alkaline phosphatase (10 units)
Relative PAP activity $(\%)$ $100(5)$

$79 \pm 6(5)$

$75 \pm 8(2)$

$71 \pm 11(2)$

$100(2)$

$76 \pm 10(2)$
1973) and hydroxymethylglutaryl-CoA reductase (Beg et al., 1973; Gibson \& Ingebritsen, 1978).

No significant effects were found on the $V_{\max }$. of PAP after incubation with $2 \mathrm{~mm}-\mathrm{MgCl}_{2}$ and $2 \mathrm{mM}$-ATP in the presence or absence of cyclic AMP (Table 2a). The small increase in PAP activity that was detected with $\mathrm{MgCl}_{2}$ and ATP was also observed if a non-phosphorylating analogue of ATP (adenosine $5^{\prime}$-[ $[\beta \gamma$-methylene $]$ triphosphate) was used to replace ATP. However, to exclude the possibility that the endogenous cyclic AMP-dependent protein kinase may have been inactivated, 4 units of purified protein kinase $/ \mathrm{ml}$ were added to the preincubation (Table $2 b$ ). This also failed to change significantly the activity of PAP. Similar results were obtained with concentrations of protein kinase of $0.66,1.32,2.64$ and 5.2 units $/ \mathrm{ml}$ (results not shown). There was also no evidence that the $K_{\mathrm{m}}$ of PAP for phosphatidate was altered when the assays were performed at rate-limiting concentrations of this substrate (results not shown). In order to confirm that proteins were phosphorylated in the system used in Table $2(b)$, parallel incubations were performed by using $\left[\gamma-{ }^{32} \mathrm{P}\right] \mathrm{ATP}$. This showed that a net incorporation of $2.9 \mathrm{nmol}$ of phosphate $/ \mathrm{mg}$ of protein was obtained after the $15 \mathrm{~min}$ incubation, compared with $0.74 \mathrm{nmol}$ in controls incubated with $[\gamma$ ${ }^{32}$ P]ATP alone.

Effects of cyclic AMP and oleate on the activity and distribution of PAP in isolated hepatocytes

In a further attempt to determine whether a cyclic AMP-dependent mechanism might modify PAP activity, studies were performed with isolated hepatocytes in the presence and absence of oleate. This fatty acid increases PAP activity, and its translocation from the cytosol to the membrane-associated compartment (Cascales et al., 1984). It also

Table 2. Effect of $\mathrm{MgCl}_{2}, \mathrm{ATP}$, cyclic AMP and cyclic AMP-dependent protein kinase on the activity of PAP in the soluble fraction of rat liver

The particle-free supernatant of rat liver was preincubated for $15 \mathrm{~min}$ at $37^{\circ} \mathrm{C}$ under the conditions indicated and samples were taken for the determination of PAP activity (see the Experimental section). The results are expressed relative to the basal activities obtained with no further additions and they are given as means \pm S.D. for the numbers of independent experiments shown in parentheses. The $100 \%$ values in sections $(a)$ and $(\bar{b})$ were $9.3 \pm 3.7$ and $8.3 \pm 3.3 \mathrm{nmol}$ of diacylglycerol formed $/ \mathrm{min}$ per $\mathrm{mg}$ of protein respectively.

Additions

(a) None

$+\mathrm{MgCl}_{2}(2 \mathrm{mM})$

$+\operatorname{ATP}(2 \mathrm{mM})$

$+\operatorname{ATP}(2 \mathrm{~mm})+\mathrm{MgCl}_{2}(2 \mathrm{mM})$

(b) None

$+\operatorname{ATP}(2 \mathrm{mM})+\mathrm{MgCl}_{2}(2 \mathrm{mM})+$ cyclic AMP $(1 \mu \mathrm{M})$

$+\mathrm{MgCl}_{2}(10 \mathrm{mM})+\mathrm{ATP}(5 \mathrm{mM})+$ cyclic AMP $(10 \mu \mathrm{M})$

$+\mathrm{MgCl}_{2}(10 \mathrm{mM})+\mathrm{ATP}(5 \mathrm{mM})+$ cyclic AMP $(10 \mu \mathrm{M})+$ protein kinase

(4 units $/ \mathrm{ml}$ )

Relative PAP activity (\%)
100
$104 \pm 14(3)$
$103 \pm 8(3)$
$111 \pm 17(3)$
$108 \pm 7(3)$
100
$96 \pm 3(4)$
$97 \pm 8(4)$


Table 3. Effects of CPT-cAMP and oleate on the activity and distribution of PAP between the cytosol and the membraneassociated compartment of rat hepatocytes

The hepatocytes were incubated for $1 \mathrm{~h}$ at $37^{\circ} \mathrm{C}$ in the presence or absence of oleate and CPT-cAMP as indicated. The medium was replaced by $1.5 \mathrm{ml}$ of an ice-cold suspension of $4.07 \mathrm{mM}$-digitonin to release selectively cytosolic enzymes (see the Experimental section). The activities of PAP in the cytosolic and membrane-associated compartments were calculated by correcting for the incomplete release of lactate dehydrogenase in the digitonin extract (Cascales et al., 1984). Results are given as means \pm S.D. for five independent experiments. The significance of the differences were calculated by using a paired $t$ test. The total PAP activity in $(a)$ was $0.68 \pm 0.57 \mathrm{nmol}$ of diacylglycerol formed/min per unit of lactate dehydrogenase.

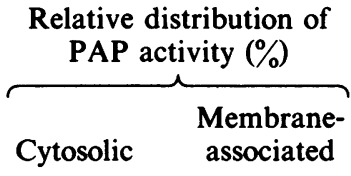

(a) None

(b) CPT-cAMP (0.5 mM)

(c) Oleate (1 mM)

(d) Oleate $(1 \mathrm{mM})+$ CPT-cAMP $(0.5 \mathrm{~mm})$

\section{Additions}

$68 \pm 14 \quad 32 \pm 14$

$86 \pm 12$

$48 \pm 8$

$40 \pm 9$
$14 \pm 12$

$52 \pm 8$

$60 \pm 9$
Significance of difference between the relative distribution of PAP

(a) versus $(b), P<0.005$

(a) versus (c), $P<0.05$

(a) versus $(d), P<0.02$

(b) versus $(d), P<0.005$

(c) versus $(d), P<0.02$
Total PAP activity relative to

(a)

100

$112 \pm 22$

$109 \pm 24$

$99 \pm 31$ reverses the effects of cyclic AMP in inhibiting the synthesis of triacylglycerols and phosphatidylcholine (Pelech et al., 1983b).

Hepatocytes were incubated with CPT-cAMP, which is an analogue that is more potent and stable than cyclic AMP itself (Miller et al., 1975). The concentration of $0.5 \mathrm{mM}$ was that used previously to inhibit triacylglycerol synthesis (Pelech et al., $1983 b$ ). The incubation with CPT-cAMP increased the total PAP activity in four independent experiments out of five, but overall this was not statistically significant $(0.1>P>0.5)$. However, it did significantly promote the translocation of the PAP from the membrane-associated compartment to the cytosol (Table 3). The relatively low concentration of $1 \mathrm{mM}$-oleate did not increase the PAP activity significantly, but it did increase the proportion of PAP in the membrane-associated compartment relative to that in the cytosol as expected from the results of Cascales et al. (1984). It also reversed the effects of CPT-cAMP in increasing the amount of PAP in the cytosol relative to that in the membrane-associated compartment. In fact, the proportion of membraneassociated PAP was higher with both CPT-cAMP and oleate present than it was with oleate alone.

\section{Discussion}

The experiments described in this paper were performed to determine whether the activity of PAP in the liver could be regulated acutely by a phosphorylation/dephosphorylation cycle involving cyclic AMP. Evidence that PAP may be a phosphorylated protein is provided by Table 1 , in which the incubation of the particle-free supernatant with alkaline phosphatase decreased the activity of PAP by $21-29 \%$. This effect could also occur if alkaline phosphatase were to degrade a low- $M_{\mathrm{r}}$ phosphate ester that activates PAP. Even if PAP can be phosphorylated this need not involve a cyclic AMP-dependent mechanism. PAP activity in hepatocytes can be increased by $30-50 \%$ when they are incubated for 5-60 min with vasopressin (Pollard \& Brindley, 1984). This could be caused by a $\mathrm{Ca}^{2+}$-dependent mechanism involving a calmodulin-dependent kinase, or protein kinase C. It was also not possible to stimulate PAP activity in the particle-free supernatant by preincubating it with various combinations of $\mathrm{MgCl}_{2}$, ATP, cyclic AMP and cyclic AMP-dependent protein kinase (Table 2). However, the incubation of hepatocytes for $1 \mathrm{~h}$ with a cyclic AMP analogue, CPT-cAMP, did result in a stimulation of the total PAP activity as measured in vitro in four out of five independent experiments (Table 3). We also know that an increase in PAP activity of 3-4-fold can be obtained when the hepatocytes are incubated for $8 \mathrm{~h}$ with $0.1 \mathrm{mM}-\mathrm{CPT}$-cAMP (R. A. Pittner \& D. N. Brindley, unpublished work). This effect could also involve a stimulation in the synthesis of PAP. However, as explained later, these increases in PAP activity may not be expressed physiologically until the hepatocytes are exposed to high concentrations of fatty acids.

These conclusions concerning the effects of alkaline phosphatase and incubating with $\mathrm{Mg}^{2+}$ and ATP are opposite to those reported by Berglund et al. (1982). In the case of alkaline 
phosphatase, Berglund et al. (1982) made no mention of any conversion of phosphatidate to diacylglycerol by the alkaline phosphatase preparation. This could have contributed to an apparent increase in PAP activity. In our work we either used an assay for PAP in which no formation of diacylglycerol was detected in incubations that contained alkaline phosphatase but not PAP, or corrected for this breakdown. It is also interesting to note that Berglund et al. (1982) were also unable to demonstrate the stimulatory effect of alkaline phosphatase if they used a particle-free supernatant as a source of PAP rather than a dialysed $\left(\mathrm{NH}_{4}\right)_{2} \mathrm{SO}_{4}$ precipitate. We were reluctant to follow this latter procedure since it was not practical to add $\mathrm{F}^{-}$and EDTA to preserve the PAP in a phosphorylated state during this treatment, since these reagents can inhibit PAP itself (Brindley \& Sturton, 1982). We had also observed that PAP is aggregated by treatment with $\left(\mathrm{NH}_{4}\right) \mathrm{SO}_{4}$ (Butterwith et al., 1984).

The technique used by Berglund et al. (1982) to phosphorylate PAP also seems to be open to some criticism since they did not control the concentration of $\mathrm{MgCl}_{2}$ present in their assay. Their basic system contained $1 \mathrm{~mm}-\mathrm{MgCl}_{2}$, which in our experience is sub-optimum for crude preparations of soluble PAP obtained from rat liver (Sturton $e t$ al., 1981; Butterwith et al., 1984). However, this may vary depending upon the physical state of the phosphatidate that is used (Brindley \& Sturton, 1982). Berglund et al. (1982) then added $4 \mathrm{~mm}-$ $\mathrm{MgCl}_{2}$ or $4 \mathrm{mM}-\mathrm{MgCl}_{2}$ plus $2 \mathrm{mM}-\mathrm{ATP}$ to the incubation medium. Chelation of $\mathrm{Mg}^{2+}$ to ATP would decrease the free $\mathrm{Mg}^{2+}$ concentration in the latter case. In the present experiments the PAP was preincubated with combinations of ATP and $\mathrm{Mg}^{2+}$, and only small samples were used for the subsequent determination of PAP activity. This would have produced only very small changes in free $\mathrm{Mg}^{2+}$ in the incubations that already contained an optimum of $5 \mathrm{mM}-\mathrm{MgCl}_{2}$. The work of Berglund et al. (1982) would have been strengthened had they demonstrated that their decrease in PAP activity did not occur if a non-phosphorylating analogue of ATP was used.

The studies with isolated hepatocytes (Table 3) also demonstrate that no decrease in PAP activity is caused by treatment with a cyclic AMP analogue. There was, however, a higher proportion of PAP in the cytosol compared with the membrane-associated compartment where glycerolipid synthesis occurs. It is likely that the cytosolic PAP forms a reservoir of potential activity that can be measured in vitro and which is expressed physiologically by translocation when the hepatocyte is required to synthesize triacylglycerol (Cascales et al., 1984). One stimulus for this occurs when the liver receives an increased supply of fatty acids from adipose tissue, which normally occurs when the concentration of cyclic AMP is raised in both of these organs. The liver protects itself against an excessive rise in the concentrations of unesterified fatty acids and acyl-CoA esters by synthesizing more triacylglycerol if the fatty acids are not removed efficiently by $\beta$-oxidation. The fatty acidinduced translocation of PAP to the membraneassociated compartment could facilitate triacylglycerol synthesis in these conditions (Cascales et al., 1984).

This translocation is also demonstrated in Table 3. Furthermore, oleate is able to reverse the effect of cyclic AMP in promoting the relative increase in cytosolic PAP. These results are essentially compatible with those of Soler-Argilaga et al. (1978) who demonstrated an increase in microsomal PAP activity when livers were perfused with $20 \mu \mathrm{M}$ dibutyryl cyclic AMP and $0.5 \mathrm{~mm}$-oleate. The results in Table 3 also explain why the inhibition of triacylglycerol synthesis that is produced by cyclic AMP analogues can be overcome when fatty acids are added to the incubation medium (Pelech et al., $1983 b$ ).

It is also evident that the control of the activities of PAP (Table 3; Cascales et al., 1984) and CTP : phosphocholine cytidylyltransferase (Pelech et al., 1983a,b; Vance \& Pelech, 1984) are very similar with respect to their translocation between different cell compartments and the effects of fatty acids and cyclic AMP. The indirect evidence in this paper and that described by Pelech et al. (1981) and Vance \& Pelech (1984) suggests that the two enzymes might be phosphorylated. The ultimate proof of this will require the demonstration of phosphopeptides derived from these enzymes. In the case of PAP, if a cyclic AMP-dependent phosphorylation occurs it need not necessarily produce obvious changes in activity when this is brought about with the cytosolic fraction alone (Table 2). However, this proposed phosphorylation in hepatocytes could decrease the ability of PAP (Table 3) and the cytidylyltransferase (Pelech et $a l ., 1983 b)$ to interact with membranes, thus requiring higher concentrations of fatty acids to effect the translocation. If this is so then a greater proportion of fatty acids should be oxidized by the liver when its cyclic AMP concentrations are high and the fatty acid flux is low. With greater availability of fatty acids the synthesis of both triacylglycerol and phosphatidylcholine is increased (Pelech et al., 1983b) resulting in a fatty liver in ketotic diabetes. However, the secretion of very-low-density lipoproteins is also increased in this condition and in stress, which requires the coordinated synthesis of both phosphatidylcholine and triacylglycerol. 
We would like to thank Professor D. E. Vance and Dr. S. L. Pelech for useful suggestions and discussions and Dr. E. D. Saggerson for his gift of cyclic-AMPdependent protein kinase. Travel grants were provided to D. E. Vance and D. N. B. by NATO (149.81) and research studentships were awarded to $\mathrm{S}$. C. B. and A. M. respectively by the Science and Engineering Research Council and the Medical Research Council. The work was also supported by a project grant from the Medical Research Council and an equipment grant from the Humane Research Trust.

\section{References}

Beg, Z. H., Allmann, D. W. \& Gibson, D. M. (1973) Biochem. Biophys. Res. Commun. 54, 1362-1369

Berglund, L., Björkhem, I. \& Einarsson, K. (1982) Biochem. Biophys. Res. Commun. 105, 288-295

Bowley, M., Cooling, J., Burditt, S. L. \& Brindley, D. N. (1977) Biochem. J. 165, 447-454

Brindley, D. N. \& Sturton, R. G. (1982) Phospholipids: New Comp. Biochem. 4, 179-213

Brostrom, M. A., Reimann, E. M., Walsh, D. A. \& Krebs, E. G. (1969) Adv. Enzyme Regul. 8, 191-203

Butterwith, S. C., Hopewell, R. \& Brindley, D. N. (1984) Biochem. J. 220, 825-833

Carlson, C. A. \& Kim, K. H. (1973) J. Biol. Chem. 248, 378-380

Cascales, C., Mangiapane, E. H. \& Brindley, D. N. (1984) Biochem. J. 219, 911-916

Gibson, D. M. \& Ingebritsen, T. S. (1978) Life Sci. 23, 2649-2664

Greenspan, M. \&. Lowenstein, J. M. (1967) Arch. Biochem. Biophys. 118, 260-263

Jennings, R. J., Lawson, N., Fears, R. \& Brindley, D. N. (1981) FEBS Lett. 113, 119-122
Lamb, R. G. \& McCue, S. B. (1983) Biochim. Biophys. Acta 753, 356-363

Lawson, N., Jennings, R. J., Fears, R. \& Brindley, D. N. (1982a) FEBS Lett. 143, 9-12

Lawson, N., Pollard, A. D., Jennings, R. J. \& Brindley, D. N. (1982b) FEBS Lett. 146, 204-208

Lehtonen, M. A., Savolainen, M. J. \& Hassinen, I. E. (1979) FEBS Lett. 99, 162-166

Mackall, J., Meredith, M. \& Lane, M. D. (1979) Anal. Biochem. 95, 270-274

Miller, J. P., Beck, A. H., Simon, L. N. \& Meyer, R. B. (1975) J. Biol. Chem. 250, 426-431

Pelech, S. L., Pritchard, P. H. \& Vance, D. E. (1981) J. Biol. Chem. 256, 8283-8286

Pelech, S. L., Pritchard, P. H., Brindley, D. N. \& Vance, D. E. (1983a) J. Biol. Chem. 258, 6782-6788

Pelech, S. L., Pritchard, P. H., Brindley, D. N. \& Vance, D. E. (1983b) Biochem. J. 216, 129-136

Pollard, A. D. \& Brindley, D. N. (1984) Biochem. J. 217, 461-469

Reimann, E. M., Walsh, D. A. \& Krebs, E. G. (1971) J. Biol. Chem. 246, 1986-1995

Rider, M. H. \& Saggerson, E. D. (1983) Biochem. J. 214, 235-246

Saggerson, E. D. \& Greenbaum, A. L. (1969) Biochem. J. 115, 405-417

Soler-Argilaga, C., Russell, R. L. \& Heimberg, M. (1978) Arch. Biochem. Biophys. 190, 367-372

Sturton, R. G. \& Brindley, D. N. (1980) Biochim. Biophys. Acta 619, 494-505

Sturton, R. G., Butterwith, S. C., Burditt, S. L. \& Brindley, D. N. (1981) FEBS Lett. 126, 297-300

Vance, D. E. \& Pelech, S. L. (1984) Trends Biochem. Sci. 9, 17-20

Walsh, D. A., Perkins, J. P., Brostrom, C. O., Ho, E. S. \& Krebs, E. G. (1971) J. Biol. Chem. 246, 1968-1976 